\title{
Problems of forming a regional quasi-market of social services: from paternalism to competition
}

\author{
A. A. Vlasova ${ }^{1}$, A.-A. V. Galanova ${ }^{1}$
}

1P. G. Demidov Yaroslavl State University, 14 Sovetskaya str., Yaroslavl 150003, Russian Federation

DOI: $10.18255 / 2412-6519-2021-3-304-317$

Research Article

The article reflects the results of the analysis of the problems of the formation of a regional quasimarket of social services using the example of the Yaroslavl region in the transition from a state monopoly to competitive relations. It was revealed that the product market boundaries and requirements for the quality of services provided were formed during the Soviet period for state and municipal social services, which creates institutional barriers to entry of socially oriented non-profit organizations into the market. The share of non-governmental social services in the provision of social services in the Yaroslavl region is no more than 20\%, and the number of NGOs officially included in the register of social service providers is 3 units. Thus, the authors concluded that the quasi-market of social services is in the process of formation, and it can be described as a "proto-market". At the same time, it was determined that social oriented NGOs have a number of competitive advantages as providers of social services - they provide low transaction costs for the recipient, an expanded range of services, a greater customer focus. The formation of a sustainable regional model of social services at this stage is associated with further diversification of the subjects of social services, expanding the product boundaries of this market, introducing innovative assistance technologies and increasing both the economic and social efficiency of social services. It seems promising to create a unified regional information system in the Yaroslavl region for providers and recipients of social services, allowing residents of the region to order social services via the Internet with the right to choose a provider and conclude contracts online through authorization on the government services portal.

Keywords: non-profit organizations; quasi-market; social service provider; paternalism; socio-economic policy; social services market; managerialism

\section{INFORMATION ABOUT THE AUTHORS}

\author{
Vlasova, Alexandra A. $\mid$ Email: fspn@bk.ru \\ (correspondence author) Cand. Sc. (Politics), Associate Professor \\ \begin{tabular}{l|l} 
Galanova, Alla-Anna V. & $\begin{array}{l}\text { Email: allaanna.post@bk.ru } \\
\text { Assistant }\end{array}$
\end{tabular}
}

For citation: Vlasova A. A., Galanova A.-A. V. Problems of forming a regional quasi-market of social services: from paternalism to competition // Social'nye i gumanitarnye znanija. 2021. Vol. 7, No 3. P. 304-317. (in Russ.)

(C) Vlasova A. A., Galanova A.-A. V., 2021

This is an open access article under the CC BY license (https://creativecommons.org/licenses/by/4.0/) 


\title{
Проблемы формирования регионального квазирынка социальных услуг: от патернализма к конкуренции
}

\author{
А. А. Власова ${ }^{1}$, А.-А. В. Галанова 1
}

1Ярославский государственный университет им. П.Г. Демидова, ул. Советская, 14, Ярославль, 150003, Российская Федерация

DOI: $10.18255 / 2412-6519-2021-3-304-317$

УдК 364.07

Научная статья Полный текст на русском языке

В статье отражены результаты анализа проблем формирования регионального квазирынка социальных услуг на примере Ярославской области в условиях перехода от государственной монополии к конкурентным отношениям. Выявлено, что продуктовые границы рынка и требования к качеству предоставляемых услуг сформированы в советский период для государственных и муниципальных социальных служб, что создает институциональные барьеры для входа на рынок социально ориентированных некоммерческих организаций (СО НКО). Доля негосударственных социальных служб в сфере предоставления социальных Ярославской области составляет не более $20 \%$, а количество СО НКО, официально включенных в реестр поставщиков социальных услуг, равняется 3 единицам. Авторами сделан вывод, что квазирынок социальных услуг находится в стадии формирования и его можно охарактеризовать как «проторынок». В то же время определено, что СО НКО обладают рядом конкурентных преимуществ: в том числе, они обеспечивают низкие трансакционные издержки для получателя, расширенный ассортимент предоставляемых услуг, большую клиентоориентированность и возможность кастомизации услуг. Формирование устойчивой региональной модели социального обслуживания связано с дальнейшей диверсификацией субъектов социального обслуживания, внедрением инновационных технологий помощи и повышением социально-экономической эффективности социального обслуживания. Перспективным представляется создание единой региональной информационной системы в Ярославской области для поставщиков и получателей социальных услуг, позволяющей жителям региона заказывать социальные услуги через сеть Интернет с правом выбора поставщика и заключением контрактов онлайн через авторизацию на портале государственных услуг.

ключевые слова: некоммерческие организации; квазирынок; поставщик социальных услуг;
патернализм; социально-экономическая политика; рынок социальных услуг; менеджерализм ИНФОРМАЦИЯ ОБ АВТОРАХ

Власова Александра Александровна (автор для корреспонденции)

Галанова, Алла-Анна Викторовна
Email: fspn@bk.ru

Кандидат политических наук, доцент, зав. кафедрой социальных технологий

Email: allaanna.post@bk.ru

Ассистент кафедры социально-политических теорий

Для цитирования: Власова А. А., Галанова А.-А. В. Проблемы формирования регионального квазирынка социальных услуг: от патернализма к конкуренции // Социальные и гуманитарные знания. 2021. Том 7, № 3. С. 304-317. 


\section{Введение}

Сфера предоставления социальных услуг - важнейшая часть жизни общества. Процессы, протекающие в ней, с одной стороны, оказывают непосредственное влияние на уровень и качество жизни граждан страны [1], с другой - являются показателем успешности и эффективности фактически всех направлений деятельности социального государства, его экономической и социальной политики. Под социальной услугой в российском законодательстве понимается «действие или действия в сфере социального обслуживания по оказанию постоянной, периодической, разовой помощи, в том числе срочной помощи, гражданину в целях улучшения условий его жизнедеятельности и (или) расширения его возможностей самостоятельно обеспечивать свои основные жизненные потребности»1.

В современных российских условиях наблюдаются как преобразования уже институционализированных практик предоставления социальных благ гражданам со стороны государственных социальных служб в традиционно патерналистском ключе, так и становление новых механизмов социального обслуживания на рыночных условиях с новыми игроками рынка.

Эти изменения являются ответной реакцией на те вызовы, с которыми сталкивается российское общество: трансформация социальной структуры (ориентация на средний класс при сильных тенденциях к поляризации [2]), смена парадигм социальной политики (отказ государства от монопольного положения в сфере предоставления социальных услуг в постсоветских странах [3; 4]) и, как следствие, диверсификация субъектов социальной политики, а также общемировая тенденция к менеджерелизации и повышению эффективности управления социальной сферой $[5 ; 6]$ в условиях возрастания требований со стороны населения к качеству, объему и ассортименту предоставляемых социальных услуг, переход к проактивной модели социальной политики и смещение ее ориентиров во многих развитых странах с негативных моментов (борьба с нищетой и бедностью) на постановку новых позитивных целей (например, на достижение такого показателя, как валовое внутреннее счастье [7]).

Договорная форма предоставления социальных услуг является основанием для возникновения рыночных или квазирыночных отношений, переводя социальное обслуживание из разряда патерналистских мер государственной заботы о благополучии граждан в категорию гражданско-правовых отношений двух активных субъектов - производителя и получателя социальных услуг [8; 9].

Появление новых активных субъектов - негосударственных некоммерческих организаций - поставщиков социальных услуг стало ответом на запросы государства и общества в сфере повышения эффективности социального обслуживания. По сведениям Минэкономразвития, в России в сфере социального обслуживания и социальной защиты на 2019 год действовало 929 социально ориентированных НКО, которым были переданы на исполнение услуги, предоставляемые за счет бюджета [10].

Все это привело к необходимости принципиальных изменений в практике социального обслуживания: как поиска новых, адекватных изменившимся условиям

\footnotetext{
${ }^{1}$ Федеральный закон от 28.12.2013 № 442-Ф3 (ред. от 13.07.2020) «Об основах социального обслуживания граждан в Российской Федерации" (ст. 3) // Справочно-правовая система КонсультантПлюс: [сайт]. URL: http://www.consultant.ru/document/cons_doc_LAW_156558/4f41fe599ce341751e4e34dc50a4b676674c1416/ (дата обращения: 20.01.2020).
} 
теоретических подходов к изучению социальных услуг, так и формирования практических моделей в этой сфере, в том числе на региональном уровне.

Целью работы является анализ формирования регионального квазирынка социальных услуг на примере Ярославской области, в частности, выявление роли негосударственных поставщиков социальных услуг в его развитии.

\section{1. Теоретические подходы к изучению проблемы}

Традиционно в экономике социальные услуги рассматривались как особого рода товар, обладающий рядом специфических признаков (одномоментность оказания и получения услуги, зависимость ее качества от профессионализма поставщика, неосязаемость, несохраняемость, асимметричность и др.) [11; 12]. Социальные услуги являются специфического рода услугами в сфере социального обслуживания для отдельных категорий населения, представляя особый тип общественных благ [13].

Термин «квазирынок» еще в начале 1980-х годов был применен Дж. Ле Грандом. Его введение ознаменовало смещение акцентов от государственного социального обеспечения к рыночному пониманию отношений производства и потребления социальных услуг. Дж. Ле Гранд определил квазирынок (по аналогии с А. Смитом «другая невидимая рука») как особый институционализированный механизм производства и распределения социальных услуг [14; 15$]$.

В российской социологии к категории квазирынков исследователи обратились значительно позднее, в конце 1990-х - начале 2000-х годов. Наиболее полно квазирынки социальных услуг описаны в докладе П. В. Романова и Е. Р. Ярской-Смирновой. [16, с. 14-17].

С. В. Суслова главным признаком квазирынка называет то, что «государство попрежнему финансирует и регулирует производство товаров и услуг, но при этом ликвидирует собственную монополию на участие в самом производственном процессе: он становится открытым для организаций всех форм собственности [17, с. 74]. При этом С. В. Якимчук отмечает: «парадокс заключается в том, что количество нуждающихся в социальной поддержке в силу таких обстоятельств, как научно-технический прогресс и достижения в области медицины, перманентно увеличивается, а феномен социальной справедливости «плохо сочетается в экономике с понятием «оптимальность». Достижение равенства и экономическая эффективность часто противоречат друг другу» [18, с. 22].

Кроме того, исследователями с позиций квазирыночных отношений в сфере социального обслуживания заново пересматриваются проблемы качества, эффективности и результативности всей системы социального обеспечения. Термин «качество» применительно к сфере оказания социальных услуг используется крайне неудачно в силу сложности оценивания нематериальных услуг и разработки прозрачных объективных критериев качественной деятельности [19, с. 87]. Дискуссионным остаётся вопрос о том, каким должен быть инструментарий, гарантирующий возможность провести реальную оценку вышеуказанных показателей [20].

Экономическое понимание социальных услуг породило, в свою очередь, маркетинговый подход к их изучению, что позволяет определить такие параметры, как продуктовые и территориальные границы рынка социальных услуг, его субъектный состав и объем, характеристики потребителей, барьеры входа на рынок, степень концентрации и конкуренции и т. п. 
В современной литературе достаточно разработаны вопросы маркетинга образовательных услуг [21; 22], услуг в области здравоохранения [23; 24]. Однако маркетинг социальных услуг в узком смысле фактически не упоминается, что связано, на наш взгляд, с патерналистским подходом к сфере социального обслуживания.

Обзор различных подходов к пониманию сущности рынка социальных услуг позволяет сделать вывод об отсутствии единой макротеории в экономических и социальных науках. Широкий подход к социальным услугам и многосубъектному рынку социальных услуг может быть основан на идеях нового социального и государственного менеджмента (New Public Management) [25; 26], что позволит ставить вопросы качества и эффективности социального обслуживания, не смещая акценты от человека как основного потребителя социальных благ к бюрократическим процедурам и административным механизмам.

\section{2. Методы исследования}

Для того чтобы обеспечить междисциплинарный подход, авторами применялись методы, характерные для маркетинговых и социологических исследований.

Выбранный подход предполагал общую характеристику рынка социальных услуг в России, определение регионального объема рынка, его сегментирование, анализ продуктовых границ, а также изучение показателей конкурентной силы и конкурентной слабости поставщиков социальных услуг.

Маркетинговый подход предполагает и такой характерный для него метод исследования, как открытый тип SWOT-анализа.

Качественная характеристика рынка была получена в ходе глубинных интервью представителей негосударственных социально ориентированных организаций, оказывающих социальные услуги населению (как входящие в реестр поставщиков социальных услуг, так и не вошедшие в него) (N=9). Топик-гайд содержал несколько смысловых блоков: проблемы входа социально ориентированных некоммерческих организаций на рынок социальных услуг в регионе, взаимодействие негосударственных и государственных (муниципальных) социальных служб в регионе, вопросы качества социальных услуг, поддержка профильными ведомствами негосударственных поставщиков социальных услуг и влияние Интернета и цифровых технологий на развитие рынка.

\section{3. Региональный ландшафт квазирынка социальных услуг в Ярославской области}

Рассмотрение регионального ландшафта социального обслуживания позволяет сформировать общую мозаичную картину социального развития общества. В Ярославской области в реестр поставщиков социальных услуг включено 58 государственных стационарных и нестационарных учреждений ${ }^{1}$. Негосударственных организаций, входящих в реестр поставщиков социальных услуг Ярославской области на 01.01.2020, насчитывается всего 3. Однако, согласно исследованиям А. В. Соколова, еще в 2015-2016 годах в Ярославской области «2/3 некоммерческих организаций, попавших в выборку исследования, уже сейчас оказывают населению социальные услуги. НКО специализируются на предоставлении бесплатных социальных услуг,

\footnotetext{
${ }^{1}$ Реестр поставщиков социальных услуг Ярославской области // Портал органов государственной власти Ярославской области [сайт]. URL: http://www.yarregion.ru/ (дата обращения: 03.01.2020).
} 
связанных с организацией досуга населения и оказанием ему информационно-консультативной помощи (в т. ч. юридической). Платные услуги в настоящий момент составляют не более 9 \% в работе общественных объединений, попавших в выборку исследования» [27].

Для оценки объема рынка социальных услуг в Ярославской области обратимся к анализу количества получателей такого вида услуг на территории региона.

Общее количество получателей социальных услуг за 2018 год, согласно официальным данным Правительства Ярославской области, составило 167726 человек (включая все виды и формы социальных услуг, предоставляемых государственными и муниципальными, бюджетными и казенными учреждениями, а также негосударственными некоммерческими организациями социального обслуживания, в том числе учреждениями социального обслуживания несовершеннолетних). При этом даже в динамике за последние несколько лет доля получателей социальных услуг в негосударственных структурах - СО НКО не превышает 20 \% (рис. 1).

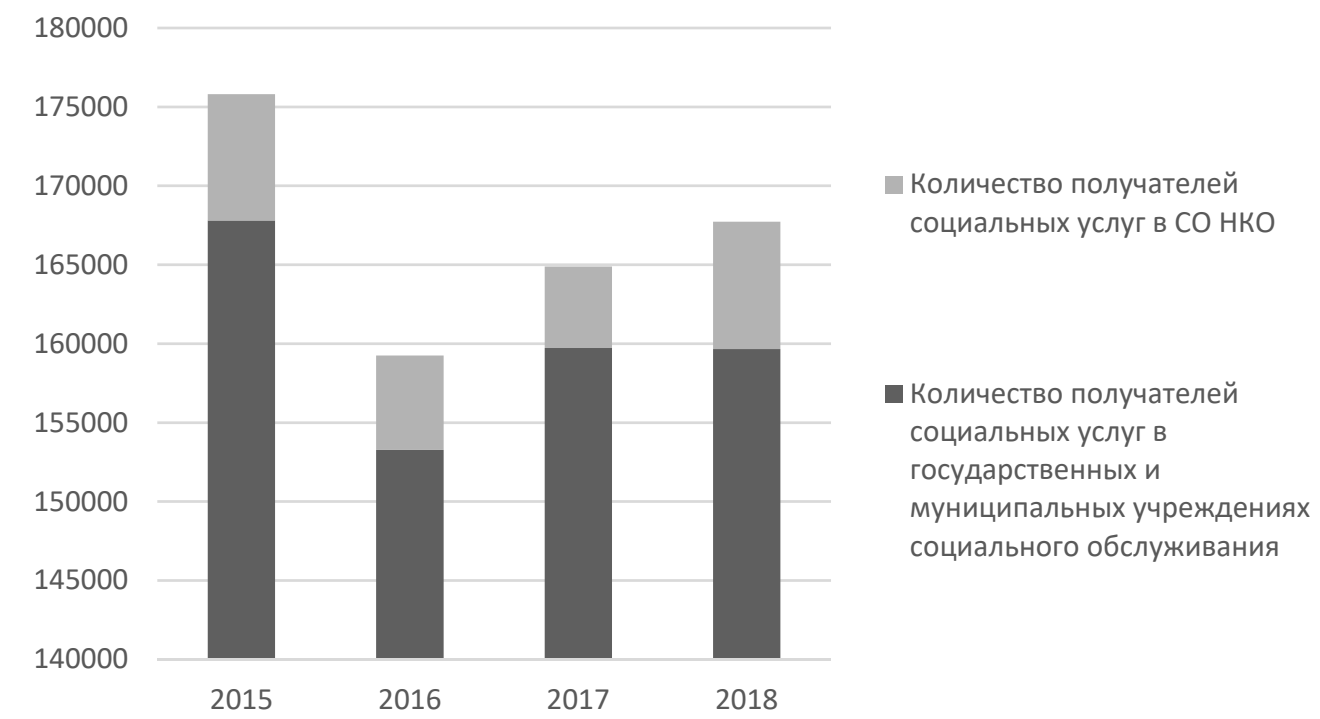

Рисунок 1. Сравнительная характеристика количества получателей социальных услуг в государственных учреждениях муниципального обслуживания населения и в социально ориентированных некоммерческих организациях

Структура субъектов социального обслуживания (исключая некоммерческие негосударственные структуры) представлена на рис. 2. Официально в реестр поставщиков социальных услуг Ярославской области включены 3 негосударственные организации, что составляет менее 10 \% от общего количества поставщиков социальных услуг, зарегистрированных в реестре. В то же время общее количество СО НКО, предоставляющих социальные услуги населению региона через механизмы государственного социального заказа, компенсации затрат поставщикам социальных услуг и конкурсных процедур, от общей численности организаций социального обслуживания всех форм собственности составило - 20 \% (14 организаций общественного сектора и 56 государственных и муниципальных служб). 


\section{Государственные бюджетные учреждения социального обслуживания Ярославской области \\ Государственные казенные учреждения социального обслуживания несовершеннолетних \\ Муниципальные бюджетные учреждения учреждения социального обслуживания Ярославской области}

Муниципальные казенные учреждения

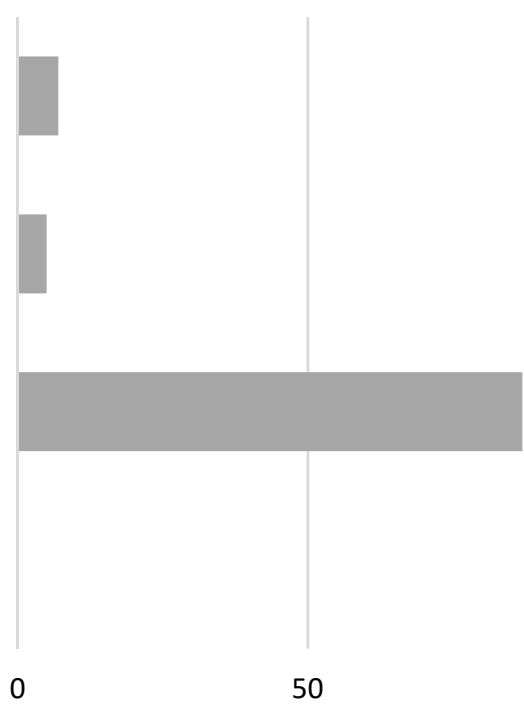

100

Рисунок 2. Доля получателей социальных услуг по организационно-правовым формам учреждений социального обслуживания в Ярославской области за 2018 г.

Для сравнения - в Финляндии доля социальных услуг, предоставляемых негосударственным сектором (включая коммерческие и некоммерческие организации), составляет в среднем $28 \%$ от общего объема услуг, при этом услуги, предоставляемые частным сектором, могут достигать $55 \%$. Во Франции государственные и муниципальные социальные службы составляют около половины всех учреждений, оказывающих услуги постоянного ухода [28], в Германии не более $7 \%$ приходится на государственные и муниципальные учреждения [29].

Что касается продуктового объема исследуемого квазирырынка, то общее количество социальных услуг, предоставляемых государственными и муниципальными учреждениями Ярославской области, только за первое полугодие 2018 года составило более 12000 единиц, что примерно равно количеству услуг, оказанных СО НКО в Ярославской области за весь 2018 год (12890 единиц).

Одним из наиболее значимых ограничивающих факторов развития конкурентных рынков социальных услуг в продуктовом разрезе, по мнению опрошенных экспертов, является то, что набор социальных услуг, а также стандарты их оказания разрабатывались для государственных социальных служб (многие из них еще в советский период). В свою очередь, данное обстоятельство зачастую не позволяет СО НКО входить на рынок с инновационными социальными решениями и технологиями социальной помощи. Из этого следует, что продуктовые границы рынка оказываются искусственно ограниченными тем спектром услуг, которые традиционно предоставляли государственные социальные службы.

Таким образом, удельный вес негосударственных организаций в общей численности организаций социального обслуживания всех форм собственности составил 20 \% (56 государственных организаций, состоящих в реестре поставщиков услуг, и 14 СО НКО, участвующих в оказании социальных услуг населению по всем существующим механизмам поддержки СО НКО). 
Отметим, что социальные службы практически не конкурируют между собой, так как имеют жесткие территориальные рамки - районы проживания обслуживаемого населения, а негосударственные СО НКО охватывают узкие сегменты потенциальных потребителей. Соответственно, говорить о наличии сопоставимых объемов предоставления социальных услуг государственными/муниципальными и негосударственными некоммерческими организации в Ярославской области, а значит, и о наличии истинной конкуренции не приходится, а квазирынок на данном зачаточном этапе становления правильнее было бы назвать «проторынком».

Оценим далее возможные направления возникновения конкурентных отношений - по качеству предоставляемых услуг.

Конкуренция на квазирынке социальных услуг фактически не является ценовой в связи с государственным регулированием тарифов, а также неготовностью большинства получателей социальных услуг оплачивать их (этот факт отметили 5 из 9 опрошенных экспертов).

Эксперты в ходе глубинных интервью отметили, что СО НКО несут большие финансовые риски - существует существенный лаг между затратами на услуги и размером компенсации за нее от государства, ряд услуг, например, полустационарное или стационарное обслуживание, практически недоступен для НКО в силу дороговизны и требований контролирующих инстанций к помещениям, в которых эти услуги предоставляются. Как отмечается в специальном докладе Общественной палаты Российской Федерации «Участие НКО в оказании услуг в социальной сфере», «тарифы и компенсации негосударственным поставщикам социальных услуг рассчитываются на основе подушевых нормативов финансирования социальных услуг» [30].

Следует отметить, что социальные услуги в форме стационарного социального обслуживания в Ярославской области оказывают только государственные социальные учреждения, СО НКО в реестре поставщиков социальных услуг Ярославской области в стационарной форме не представлено. Следовательно, государственные учреждения являются монополистами в этом сегменте рынка социальных услуг.

Надомное социальное обслуживание, таким образом, является единственным сегментом рынка, на котором представлены СО НКО, вошедшие в реестр поставщиков социальных услуг.

Вторичный анализ результатов независимой оценки качества работы учреждений социального обслуживания Ярославской области, осуществляемой Общественным советом при Департаменте труда и социальной поддержки населения Правительства Ярославской области, позволил авторам сделать следующие выводы.

У государственных учреждений социального обслуживания обнаружены низкие нормативные значения по шкале удовлетворенность условиями оказания социальных услуг (83,6 балла), несколько выше - 87,24 балла - по шкале «доброжелательность, вежливость работников организации социальной сферы».

У СО НКО, напротив, показатели по шкалам «доброжелательность и вежливость сотрудников» и «удовлетворенность условиями оказания социальных услуг» выше - 85,9 и 94,16 балла соответственно (рис. 3). Очень низко получатели социальных услуг оценили доступность услуг для инвалидов - 17,63 балла - это самый низкий показатель среди всех учреждений социального обслуживания в Ярославской области.

В целом отметим, что оценка качества оказываемых социальных услуг у государственных учреждений значительно выше практически по всем показателям, что, 
вероятнее, связано со спецификой проведения опросов клиентов социальных служб. По мнению, высказанному экспертами в ходе глубинных интервью, качество предоставляемых негосударственными службами услуг может соответствовать качеству социальных услуг государственных и муниципальных социальных служб в Ярославской области: «Есть свои плюсы и минусы и у НКО и у государственных служб», «Объективно качество предоставляемых СО НКО услуг не хуже, чем соответствующие услуги, например, в комплексных территориальных центрах социального обслуживания».

Открытость и доступность информации об организации социальной сферы

Комфортность предоставления услуг, в том числе время ожидания предоставления социальной услуги

Доступность услуг для инвалидов

Доброжелательность, вежливость работников организации социальной сферы

Удовлетворенность условиями оказания социальной услуги

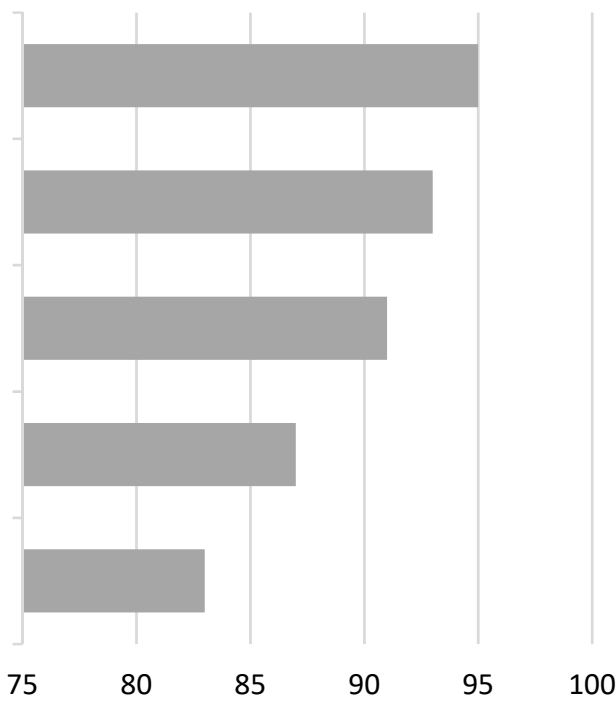

Рисунок 3. Оценка качества социальных услуг, предоставляемых СО НКО в форме социального обслуживания на дому ${ }^{1}$.

На основании мнений экспертов, полученных в ходе интервью, а также основываясь на данных ежегодного доклада Общественной палаты Ярославской области за 2015-2018 годы и специального доклада Общественной палаты России «Участие CO НКО в оказании социальных услуг) за 2018 год, авторы провели SWOT-анализ деятельности негосударственных некоммерческих организаций-поставщиков социальных услуг в Ярославской области, представленный в таблице 1.

Полученные в ходе анализа выводы интересно сопоставить с анализом деятельности государственных (муниципальных) социальных служб. Так, в качестве угроз в ходе аналогичного SWOT-анализа деятельности территориальных центров социального обслуживания были названы такие факторы, как патерналистское и иждивенческое восприятие социальной поддержки населением, неготовность получать социальные услуги на коммерческой основе, конфликтные отношения получателей социальных услуг и сотрудников социальных служб [31, с. 139].

\footnotetext{
${ }^{1}$ Составлено авторами на основании Протокола заседания Общественного совета при Департаменте труда и социальной поддержки населения Ярославской области от 23.10.2019 № 3. URL: https://www.yarregion.ru/depts/dtspn/Pages/NezOtsenkaKachestva.aspx
} 


\section{SWOT-анализ деятельности социально ориентированных некоммерческих организаций на региональном квазирынке социальных услуг в Ярославской области}

\begin{abstract}
Сильные стороны
Предоставление социальных услуг тем категориям граждан, которые не охвачены деятельностью государственных или муниципальных социальных служб (бездомные, молодые люди с ментальными нарушениями, отдельные категории семей).
\end{abstract}

Предоставление тех видов социальных услуг, которые не предоставляются государственными или муниципальными социальными службами (услуга сиделок, сопровождаемое проживание, организация досуга и развития коммуникативного потенциала для отдельных категорий граждан).

Снижение трансакционных издержек для получателей социальных услуг (отсутствие бюрократических процедур, необходимых для получения социальных услуг у негосударственных организаций).

Индивидуальный подход к получателям социальных услуг (от которого во много зависит качество услуг) обеспечивается за счет небольшой клиентской базы СО НКО и их более полного понимания нужд отдельных клиентов или категорий получателей.

Готовность к инновациям, использование инновационных технологий социальной работы в деятельности СО НКО, большая гибкость.
Слабые стороны

Проблемы финансирования (все опрошенные эксперты указали на эту слабую сторону, вне зависимости от форм поддержки СО НКО государством - будь то муниципальный или государственный заказ, компенсация затрат на предоставление общественно полезных услуг, гранты, субсидии, пожертвования).

Институциональные ограничения входа на рынок - барьеры, связанные с требованиями к видам и формам услуг (инновационные формы или виды услуг, предлагаемые СО НКО, могут не попадать под номенклатуру услуг, разрабатывавшуюся для государственных (муниципальных) служб, а также не вписываться в стандарты оказания услуг, также ориентированные на государственные службы, например, иппотерапия).

Низкий ресурсный потенциал СО НКО (эксперты отметили наличие жестких санитарно-гигиенических и пожарных требований к помещениям для стационарных форм социального обслуживания при высокой стоимости оборудования, а также необходимость создания доступной среды для инвалидов при отсутствии дополнительных источников финансирования на эти нужды для СО НКО).

Низкий уровень информированности получателей социальных услуг о деятельности СО НКО (отметим, что фактор недоверия потенциальных клиентов к СО НКО не был указан ни одним из опрошенных экспертов).

Низкий уровень платежеспособности получателей социальных услуг в силу особенностей их социально-экономического статуса (в сочетании с более высокими тарифами, чем в государственных (муниципальных) учреждениях) делает СО НКО менее конкурентоспособными). 
Продолжение таблищы 1

\begin{abstract}
Возможности
Увеличение доли СО НКО на региональном рынке социальных услуг - как за счет большего охвата потребителей, так и за счет расширения перечня оказываемых услуг.

Дальнейшая профессионализация сектора социальных услуг (как государственных, так и негосударственных) и, как следствие, повышение эффективности работы социальных служб всех организационно-правовых форм.
\end{abstract}

Внедрение новых форм поддержки СО НКО со стороны региональных органов власти (например, введение потребительских сертификатов) и дальнейшее совершенствование нормативно-правовой базы, направленной на повышение роли СО НКО в оказании социальных услуг населению региона.

Привлечение волонтерского ресурса, в том числе интеллектуального.
Угрозы

Формальное исполнение региональными и муниципальными органами власти мер по поддержке включения СО НКО в оказание социальных услуг населению.

Усиление конкуренции со стороны государственных и муниципальных социальных служб нерыночными методами - за счет административного ресурса.

Снижение спроса (возможно сокращение численности отдельных категорий получателей социальных услуг или снижение их платежеспособности).

В целом проведенный анализ позволяет вычленить конкурентную силу СО НКО как поставщиков социальных услуг: большая гибкость, инновационность, ориентация на узкие категории потребителей, а значит, более внимательное отношение к их нуждам и потребностям, работа с теми клиентами, которые не входят в системы оказания помощи государственными службами, а также предоставление расширенного спектра социальных услуг.

В качестве конкурентной слабости СО НКО эксперты в ходе интервью отметили:

- проблемы финансирования (100 \% из числа опрошенных);

- слабую ресурсную базу («Очень сложно конкурировать. Например, чтобы зайти в полустационарные услуги, надо обеспечить требования государства, стоящие немалых денег, - пожарная сигнализация, доступная среда, медицинский кабинет и т. д. Государственные организации финансируются государством, в том числе и на эти статьи, у НКО такого финансирования нет»);

- ригидность институциональной среды («Перечень услуг, тарифы и требования к ним должны быть гибкими и быстро подстраиваться под требования получателей. Процесс «заведения» новой услуги составляет от 6 месяцев до года»).

Эффективное функционирование любого рынка требует полноты информации для потребителя о видах и формах предоставляемых услуг и их качестве у разных поставщиков. Интернет и технологии на его основе способны обеспечить потребителей социальных услуг полной информацией о наличии возможностей, создать безбарьерную среду для различных категорий получателей услуг, что, в свою очередь, позволит реализовать один из основных принципов социального государства - равенство прав и недискриминационный доступ к услугам и большую социальную справедливость в обществе [32]. 
Органы социальной защиты населения Ярославской области с использованием автоматизированной информационной системы «Единый социальный регистр населения Ярославской области» (АС ЕСРН ЯО) направили в различные ведомства свыше 238 тысяч межведомственных запросов в электронном виде [33]. Согласно Ежегодному докладу о состоянии гражданского общества за 2018 год, 75,3 \% опрошенных представителей регионального интернет-сообщества отметили повышение доступности государственных и муниципальных услуг, предоставляемых в электронном виде в Ярославской области. 34,6 \% из них в течение года лично воспользовались возможностью электронного получения государственной/муниципальной услуги. Воспользовались электронными услугами некоммерческих организаций 13,4 \% регионального интернет-сообщества (что на 5 процентных пунктов выше, чем в 2017 году) [34]. Наряду с этим необходимо отметить более активное и ориентированное на целевую аудиторию цифровое представительство СО НКО.

В связи с этим перспективным представляется создание единой региональной информационной системы в Ярославской области для поставщиков и получателей социальных услуг, позволяющей жителям региона заказывать социальные услуги через сеть Интернет с правом выбора поставщика и заключением контрактов онлайн через авторизацию на портале государственных услуг.

В целом тенденция к «цифровизации» социального обслуживания может быть оценена как перспективная, снижающая трансакционные издержки и барьеры доступа к рынку социальных услуг как со стороны их получателей, так и со стороны новых игроков рынка в лице социально ориентированных некоммерческих организаций, а значит, способствующая развитию квазирыночных отношений в сегменте предоставления социальных услуг.

\section{Заключение}

Проведенное исследование особенностей квазирынка социальных услуг в Ярославской области позволяет предположить, что формирование устойчивой региональной модели социального обслуживания на данном этапе связано с дальнейшей диверсификацией субъектов социального обслуживания, расширением продуктовых границ этого рынка, внедрением инновационных технологий помощи и повышением как экономической, так и социальной эффективности социального обслуживания.

В ходе исследования был выявлен ряд ограничений, не позволяющих СО НКО стать полноценными игроками регионального квазирынка. Большая их часть, по мнению экспертов, лежит в сложившейся в советский период институциональной среде социального обслуживания, выстроенной в патерналистской философии, и соответствующим этой концепции психологии и поведении потребителей. Необходимо учитывать, что создание и поддержание конкурентных отношений на квазирынке социальных услуг не является самоцелью, оно лишь должно способствовать наиболее оптимальному удовлетворению социальных потребностей общества, обеспечивать устойчивое развитие, отвечать социально-демографическим и социально-структурным изменениям. Расширение субъектного состава сферы социального обслуживания должно способствовать достижению социального благополучия как отдельного человека, региональных сообществ, так и общества в целом. 


\section{Ссылки / References}

1. Kendall J., Knapp M., Forder J. Social care and the nonprofit sector in the western developed world // The nonprofit sector: a research handbook. 2006. Vol. 2. P. 415-431.

2. Бобков В. Н, Колмаков И. Б. Выявление социальной структуры и неравенства распределения денежных доходов населения Российской Федерации // Экономика региона. 2017. № 4. С. 971-984.

3. Koldinská K. Social services in accession countries // Social Work \& Society. 2004. Vol. 2. № 1. P. 110-117.

4. Avlijas S. Social policy reform: financing social services - practical lessons from Slovakia // Slovak-Serbian EU Enlargement Fund. 2015. P. 54-64.

5. Kaboolian L. The new public management: challenging the boundaries of the management vs. administration debate // Public Administration Review. 1998. Vol. 58. № 3. P. 189--193.

6. Романов П. В., Ярская-Смирнова Е. Р. Менеджериализация в социальной работе и социальной политике // Социальная работа: теории, методы, практика. Материалы интернет-конференций и семинаров. 2012. № 2. С. 10-12.

7. Veenhoven R. Happiness in nations: Subjective appreciation of life in 56 nations 1946-1992 // World Database of Happiness. 2001. Vol. 44. № 6. P. 231-235.

8. Барков А. В. Рынок социальных услуг: проблемы правового регулирования: автореф. дис. ... д-ра юрид. наук. М., 2009.

9. Попова Д. Г. Услуга как объект гражданских прав и ее соотношение с категорией «Социальная услуга» // Вестник КемГУ. 2012. №1. С. 351-358.

10. Участие НКО в оказании услуг в социальной сфере. Специальный Доклад Общественной палаты Российской Федерации // Общественная палата Российской Федерации [сайт]. URL: https://www.oprf.ru/files/1_2019dok/doklad_uchastie_NKO_socuslugi05112019.pdf (дата обращени: 21.01.2020).

11. Neergaard U. Social Services in General Interest in EU. T.M.C. Asser Press. 2013. 505 p.

12. Mulgan G. Measuring social value // Stanford social innovation review. 2010. № 3. P. 38-43.

13. Samuelson P. A. The pure theory of public expenditure // The Review of Economics and Statistics. 1954. Vol. 36. № 4. P. 387-389.

14. Le Grand J. The other invisible hand: delivering public services through choice and competition. Princeton: Princeton University Press, 2009. 208 p.

15. Le Grand J. Quasi-Markets and Social Policy // The Economic Journal. 1991. Vol. 101. № 408. P. 1256-1267.

16. Романов П. В., Ярская-Смирнова Е. Р. Квазирынки социальных услуг // Социальная работа: теории, методы, практика. Материалы интернет-конференций и семинаров. 2012. № 2. С. 14-17.

17. Суслова С. В. Некоммерческие производители на региональных квазирынках социальных услуг // Вопросы государственного и муниципального управления. 2014. № 3. C. 72-89.

18. Якимчук С. В. Формирование и развитие инновационной системы управления социальной защитой в интересах роста человеческого капитала: теория, методология, практика // Отечественный журнал социальной работы. 2016. № 4. С. 11-31.

19. Сухов А. Н., Гераськина М. Г., Захарова А. А. Доверие клиентов к социальным работникам // Отечественный журнал социальной работы. 2016. № 4. С. 86-91. 
20. Romanov P. Quality evaluation in social services: challenges for new public management in Russia // Mixes, Matches, and Mistakes: New Public Management in Russia and the Former Soviet Republics. Budapest: LGI, OSI, 2008. P. 9-53.

21. Allen R., Burgess S. The future of competition and accountability in education. London: Public Services Trust at the RSA, 2020. 29 p. URL:

http://www.2020publicservicestrust.org/downloads/9_The_Future_of_Competition_and_Acco untability_in\%20Education.pdf (date of access: 02.02.2020).

22. Ожерельева Т. А. Развитие маркетинга образовательных услуг // Перспективы науки и образования. 2014. № 4. С. 153-156.

23. Flynn R., Pickard S., Williams G. Contracts and the quasi-market in community health services // Journal of Social Policy. 1995. Vol. 24. № 4. P. 529-550.

24. Поляков И. В., Зеленская Т. М., Чернов А. Е. Развитие маркетинга медицинских услуг в коммерческих организациях // Экология человека. 2004. № 4. С. 54-56.

25. Osborne S. P. The new public governance // Public Management Review. 2006. Vol. 8. № 3. P. 377-387.

26. Thynne I. Making sense of public management reform: driver and supporters in comparative perspective // Public Management Review. 2003. № 5. P. 449-459.

27. Соколов А. В., Фролов А. А. Некоммерческий сектор Ярославской области: оценка эффективности деятельности в 2015 г. // Власть. 2016. № 8. С. 74-78.

28. Study on Social Services of General Interest Final Report. European Commission // Official website of the European Commission. URL: http://ec.europa.eu/social/main.jsp?catId=794 (date of access: 06.02.2020).

29. Polacek R., McDaid D. Study on social services of general interest final report // LSE Research Online. 2012. URL:

https://eprints.lse.ac.uk/43342/1/study_on_social_services_of_general_interest $\% 28 L S E R 0 \% 2$ 9.pdf (date of access: 06.02.2020).

30. Участие НКО в оказании услуг в социальной сфере. Специальный Доклад Общественной палаты Российской Федерации. М., 2019 // Общественная палата Российской Федерации : [сайт]. URL: https://opuo.ru/wpcontent/uploads/2020/02/doklad_uchastie_NKO_socuslugi05112019.pdf (дата обращения: 21.01.2020).

31. Лотова И. П. Оценка эффективности деятельности учреждения социального обслуживания // Отечественный журнал социальной работы. 2016. № 4. С. 136-147.

32. Pestoff V., \& Brandsen T. Public Governance and the third sector: opportunities for coproduction and innovation? // Conference of the European Group of Public Administration. 2009. URL: http://citeseerx.ist.psu.edu/viewdoc/download?doi=10.1.1.951.5418\&rep=rep1\&type=pdf (дата обращения: 15.02.2020).

33. Оказание государственных услуг в электронном виде и межведомственное взаимодействие в рамках АС ЕСРН ЯО. Методические рекомендации Департамента труда и социальной поддержки населения Ярославской области. Ярославль. Департамент труда и социальной поддержки населения Ярославской области, 2018. 40 с.

34. Доклад о состоянии гражданского общества в Ярославской области в 2018 году. 2019. 144 c. // Общественная палата Ярославской области [сайт]. URL: https://opyo.yarregion.ru/documents/doklady/ (дата обращения: 05.01.2020). 